\title{
Resolving the internal and basal geometry of ice masses using imaging phase-sensitive radar
}

\author{
TUN JAN YOUNG, ${ }^{1,2}$ DUSTIN M. SCHROEDER, ${ }^{3}$ POUL CHRISTOFFERSEN, ${ }^{1}$ \\ LAI BUN LOK, ${ }^{4}$ KEITH W. NICHOLLS, ${ }^{2}$ PAUL V. BRENNAN, ${ }^{4}$ SAMUEL H. DOYLE, ${ }^{5}$ \\ BRYN HUBBARD, ${ }^{5}$ ALUN HUBBARD ${ }^{6}$ \\ ${ }^{1}$ Scott Polar Research Institute, University of Cambridge, Lensfield Road, Cambridge, UK \\ ${ }^{2}$ British Antarctic Survey, National Environmental Research Council, High Cross, Cambridge, UK \\ ${ }^{3}$ Department of Geophysics, Stanford University, Stanford, CA, USA \\ ${ }^{4}$ Department of Electronic \& Electrical Engineering, University College London, Torrington Place, London, UK \\ ${ }^{5}$ Centre for Glaciology, Department of Geography \& Earth Sciences, Aberystwyth University, Aberystwyth, UK \\ ${ }^{6}$ Centre for Arctic Gas Hydrate, Environment and Climate, Department of Geology, the Arctic University of Norway, \\ Tromsø, Norway \\ Correspondence: T. J. Young <tjy22@cam.ac.uk>
}

\begin{abstract}
The phase-sensitive radio-echo sounder (pRES) is a powerful new instrument that can measure the depth of internal layers and the glacier bed to millimetre accuracy. We use a stationary 16-antenna pRES array on Store Glacier in West Greenland to measure the three-dimensional orientation of dipping internal reflectors, extending the capabilities of pRES beyond conventional depth sounding. This novel technique portrays the effectiveness of pRES in deriving the orientation of dipping internal layers that may complement profiles obtained through other geophysical surveying methods. Deriving ice vertical strain rates from changes in layer depth as measured by a sequence of pRES observations assumes that the internal reflections come from vertically beneath the antenna. By revealing the orientation of internal reflectors and the potential deviation from nadir of their associated reflections, the use of an antenna array can correct this assumption. While the array configuration was able to resolve the geometry of englacial layers, the same configuration could not be used to accurately image the glacier bed. Here, we use simulations of the performance of different array geometries to identify configurations that can be tailored to study different types of basal geometry for future deployments.
\end{abstract}

KEYWORDS: Arctic glaciology, glaciological instruments and methods, ground-penetrating radar, radio-echo sounding

\section{INTRODUCTION}

Over the last 50 years, the Greenland and Antarctic ice sheets have been extensively surveyed using radio echo sounding (radar), allowing researchers to determine ice thickness and internal stratigraphy of these large ice bodies (e.g. Evans and Smith, 1969; Harrison, 1973; Robin and others, 1977; Drewry and Meldrum, 1978; Dahl-Jensen and others, 1997; Lythe and others, 2001; Paden and others, 2010; Bamber and others, 2013; Keisling and others, 2014; MacGregor and others, 2015) and revealing insights into their past and present flow dynamics (e.g. King and others, 2009; Sime and others, 2014; Bingham and others, 2015; MacGregor and others, 2015; Winter and others, 2015; Cavitte and others, 2016; Christianson and others, 2016). While the majority of glaciological radar studies were conducted using airborne surveys or ground-based traverses, stationary phase-sensitive radio echo sounders (pRES) have recently emerged as an important tool to measure one-dimensional (I-D) vertical strain on ice sheets (Kingslake and others, 2014; Nicholls and others, 2015; Kingslake and others, 2016) and basal melting on ice shelves (Corr and others, 2002; Jenkins and others, 2006; Dutrieux and others, 2014; Marsh and others, 2016) with both high accuracy and precision.

Nicholls and others (2015) and Lok and others (2015) briefly described the potential of pRES to be deployed in an imaging mode using a multiple-input multiple-output (MIMO) array system, which has the capability to sequentially switch between up to eight transmitting (Tx) and receiving (Rx) antennas (yielding up to 64 virtual antenna pairs) with the aim to image the basal topography of ice sheets. Similar to phased arrays, a MIMO system involves the transmission and reception of its signals (and combinations thereof) from multiple transmitting and receiving antennas, arranged in such a way to create a gridded synthetic aperture from the midpoints of each virtual antenna pair. The combined signals from the antennas are then manipulated to electronically steer the array's radiation pattern in desired directions. Although the use of phased and MIMO arrays for through-air imaging are developing traction due to their wide virtual aperture and high accuracy in detecting and tracking moving targets (e.g. Li and others, 2008), its application to subsurface imaging through ice is rare. While previous studies have implemented synthetic aperture experiments to image englacial and subglacial waterways and geometries by manually moving the antenna across gridded points on the glacier surface (Walford and Harper, 1981; Kennett, 1989; Walford and Kennett, 1989), only recently have radars been able to successfully and instantaneously image the full 3-D subglacial topography using multiple antennas (Paden and others, 2010; Jezek and others, 2011; Wu and others, 2011). 
Here, we use a MIMO pRES array with 16 real antennas on Store Glacier in West Greenland to explore its imaging capabilities. We investigate the geometry of internal layers and the glacier bed obtained from three field sites. Additionally, by investigating the effects of antenna array parameters that control the radiation patterns, we demonstrate the importance of the array configuration on the resulting imagery. Finally, we highlight key array parameters to be considered in future pRES system deployments.

\section{METHODS}

\subsection{Location and study area}

Store Glacier (Qarassap Sermia) is a fast-flowing, marineterminating glacier in the Uummannaq region in western Greenland (Qaasiutsup Kommunia; Fig. 1a). The glacier has a catchment of $35000 \mathrm{~km}^{2}$ and is $5 \mathrm{~km}$ wide at the terminus, where the glacier flows at $\sim 6300 \mathrm{~m} \mathrm{a}^{-1}$ (Rignot and Mouginot, 2012; Morlighem and others, 2016). While many surrounding glaciers have recently experienced dynamic thinning due to acceleration and retreat of their termini, Store Glacier has exhibited little change in both mass balance and overall terminus position since 1968, exhibiting only a $200 \mathrm{~m}$ seasonal oscillation in the terminus position (Weidick, 1995; Howat and others, 2010; Box and Decker, 2011). This stability is due to topographic narrowing and grounding near the glacier's terminus (Todd and Christoffersen, 2014; Morlighem and others, 2016). However, with a 1000 m-deep trough extending $30 \mathrm{~km}$ inland from the margin, Store Glacier may experience rapid and prolonged retreat if the terminus stability is undermined by warming ocean temperatures (Morlighem and others, 2016).

Our study area, S30, is within $1 \mathrm{~km}$ of the central flowline, $\sim 30 \mathrm{~km}$ inland of Store Glacier's calving front (Fig. 1a), with an ice thickness between 600 and $650 \mathrm{~m}$ $\left(70^{\circ} 31^{\prime} \mathrm{N}, 49^{\circ} 56^{\prime} \mathrm{W}\right.$; Fig. 1b). Here, the glacier exhibits a moderate seasonal change in ice velocities, increasing from $\sim 600 \mathrm{~m} \mathrm{a}^{-1}$ in winter and spring to $\sim 700 \mathrm{~m} \mathrm{a}^{-1}$ when the surface meltwater accesses the subglacial environment (Doyle and others, 2018). In general, the local ice thickness increases across-flow towards the north (Fig. 1b) and drapes consistently with the bed downstream (Fig. 1d), while to the south, the flow is constrained by increasing bed elevation (Fig. 1c). Though vertically offset by 0-100 m at several locations (e.g. at the $400 \mathrm{~m}$ marker in Fig. 1d), the bed elevation profiles obtained from pRES bed soundings show similar trends of topographic change compared with other catchment-wide interpolations of bed topography, for example, calculated from mass conservation (Fig. 1c,d; Morlighem and others, 2017).

\subsection{Radar and antenna array architecture}

Over three-field campaigns (Table 1 ), three identical pRES instruments were deployed in an $8 \times 8 \mathrm{MIMO}$ array arrangement within S30 (Fig. 1b). The pRES instrument operates over the frequency range $200-400 \mathrm{MHz}$ and is centred at 300 $\mathrm{MHz}$, which allows for sufficient ice penetration while its phase sensitivity allows it to achieve millimetre-depth precision. The design and technical details for the instrument's radar board are described in detail in Brennan and others
(2014) and the practical aspects and limitations of its deployment in a quasi-monostatic ( $1 \mathrm{Tx} / 1 \mathrm{Rx}$ ) configuration are presented in Nicholls and others (2015).

The MIMO array used in the field experiments consisted of two rows of antennas on the ice surface oriented orthogonal to each other (Fig. 2a) and mounted on a wooden frame to stabilise the arrangement against differential ablation on the ice-sheet surface (Fig. 2c). Each row comprised eight cavity-backed bowtie antennas functioning in either transmit (Tx) or receive (Rx) mode, therefore synthesising a planar grid of 64 virtual antenna pairs (Lok and others, 2015), each recording one chirp for a burst total of 64 chirps $(\sim 1$ min duration). All bowtie antennas were constructed in-house for a centre frequency $f_{\mathrm{C}}=300 \mathrm{MHz}$ with a bandwidth of 200 $\mathrm{MHz}$. The dimensions of the antenna used in this study were tuned to operate on the ice surface and each was housed in a square corrugated plastic box of dimensions $820 \mathrm{~mm} \times 820 \mathrm{~mm} \times 300 \mathrm{~mm}$ (Fig. 2). Each row of antennas were arranged end-to-end, thus giving a virtual antenna pair separation of $\delta=410 \mathrm{~mm}$ (equivalent to $0.74 \times \lambda_{\mathrm{c}^{\prime}}$, the central wavelength, assuming a dielectric constant of ice of $\left.\varepsilon_{r}=3.18\right)$.

\subsection{Digital signal processing}

In addition to the processing steps described in Brennan and others (2014), we processed each of the 64 virtual antenna pairs using exact geometrical correction based on path lengths Eqn (1). This method is a direct and convenient way of processing the image in horizontal depth layers and sequentially building a 2- to 3-D depth image. Here, the beam is digitally steered by manipulating the received phase signals of each virtual antenna pair from a desired angle of incidence through combinations of constructive and destructive interference. Through this technique, the overall antenna array can scan rapidly through both the along- and cross-range of the incident ice column.

Denoting the range profile of the $\left(x_{m}, y_{n}\right)$ pixel by $E\left(x_{m}\right.$, $\left.y_{n,} r\right)$, the $(X, Y)$ pixel amplitude at a specified depth beneath the ice surface $R$ is:

$$
\begin{aligned}
P(X, Y)= & \sum_{m=1}^{M} \sum_{n=1}^{N} E\left(x_{m}, y_{n}, d\left(X, Y, x_{m}, y_{n}\right)\right) \\
& \exp \left[-j \frac{4 \pi d\left(X, Y, x_{m}, y_{n}\right)}{\lambda_{c}}\right]
\end{aligned}
$$

where $\lambda_{\mathrm{c}}$ is the wavelength corresponding to the pRES chirp's centre frequency and where $d$ is the trigonometric distance from $\left(x_{m}, y_{n}\right)$ to $(X, Y)$ :

$$
d\left(X, Y, x_{m}, y_{n}\right)=\sqrt{\left(X-x_{m}\right)^{2}+\left(Y-y_{n}\right)^{2}+R^{2}}
$$

so that when the angle of incidence is $0, d=R$.

The exponent in Eqn (1) encompasses the phase of the up-chirp:

$$
\phi=\frac{+4 \pi d}{\lambda_{\mathrm{c}}}
$$

and so the compensation is the negative of this term.

For the experiments presented herein, we use $M=N=$ 100 and a depth range of 10-650 m with a depth step of $1 \mathrm{~m}$. 

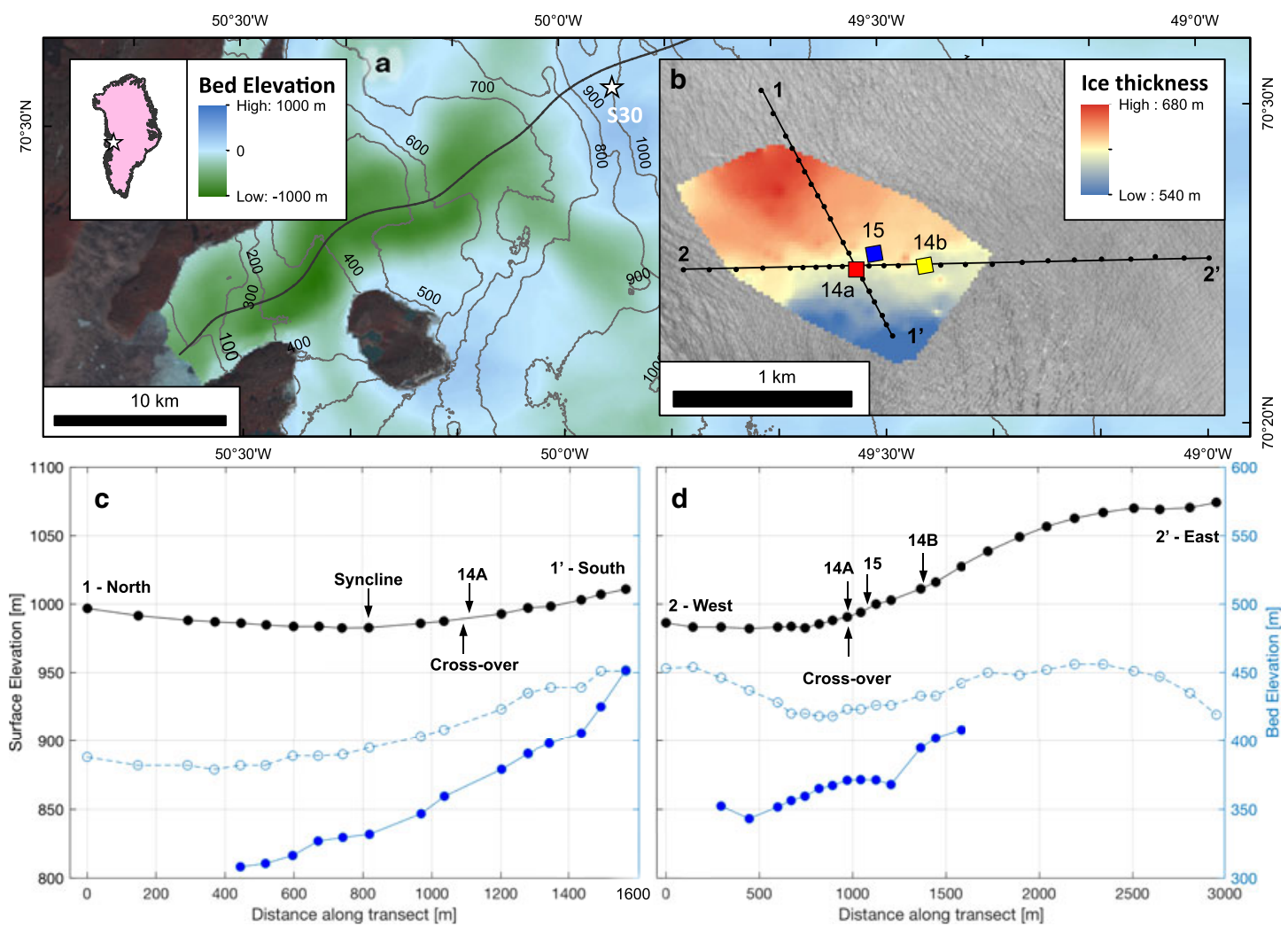

Fig. 1. (a) Map of Store Glacier and location of study area (S30), with bed elevation (Morlighem and others, 2017) overlain with surface elevation contours (GIMP DEM; Howat and others, 2014) and central flowline (thick black; Todd and Christoffersen, 2014). (b) Study area (S30) showing the location and orientation of the three radar arrays and the local ice thickness, interpolated from quasi-monostatic (1Tx/1Rx) pRES measurements. Map is superimposed on a WorldView-2 image at $2 \mathrm{~m}$ resolution (27 July 2008). (c) Surface (black) and bed (solid blue) elevation profiles obtained by subtracting the pRES-measured ice thickness from GPS-measured surface elevation measurements (Hofstede and others, 2018). The bed elevation obtained through mass conservation (dashed blue; Morlighem and others, 2017) is provided for comparison. The transect (1 to $1^{\prime}$ ) is from north to south. (d) Same as (c) but for the transect (2 to 2') running from west to east.

\subsection{2-D and 3-D vertical section processing}

Using the resulting 3-D images, we extracted 2-D horizontal and vertical cross-sections for analysis (Fig. 3). Horizontal sections are aligned parallel (i.e. along the $X-Y$ plane) and vertical sections are aligned orthogonal to the pRES synthetic aperture (i.e. along the $X-Z$ and the $Y-Z$ plane; Fig. 3). To minimise the effect of instrumental and environmental noise, all horizontal and vertical sections were subjected to first a 2-D median filter consisting of a $4 \times 4$ matrix moved over the image, and then a 2-D peak convolution using a Gaussian low-pass filter with the same moving matrix dimensions. While the post-filtering location and shape of internal layers did not significantly change when varying the window size, filtering reduced the amount of erroneous internal layers (identified through an automated peak-detection function) by $\sim 85 \%$.

With the exception of the deployment at site $14 \mathrm{a}$, which was aligned to true north resulting in a slight offset of $12^{\circ}$ relative to the principal flow direction $\left(262^{\circ}\right)$, all arrays

Table 1. Timing and orientation of radar arrays as shown in Fig. $1 \mathrm{~b}$

\begin{tabular}{lll}
\hline Site & Date/Time [UTC] & Orientation $^{\mathrm{a}}\left[{ }^{\circ}\right]$ \\
\hline $14 \mathrm{a}$ & $20: 46$ 6 May 2014 & +12 \\
$14 \mathrm{~b}$ & $17: 55$ 3 August 2014 & 0 \\
15 & $19: 405$ July 2015 & 0 \\
\hline
\end{tabular}

\footnotetext{
${ }^{a}$ Relative to the principal flow direction $\left(262^{\circ} ; \mathrm{W}\right.$ of SW).
}

were oriented relative to flow (Table 1). Therefore, while the vertical images obtained beneath sites $14 \mathrm{~b}$ and 15 depict the ice column oriented parallel and perpendicular to flow, the image obtained beneath site $14 \mathrm{a}$, respectively depict the ice column oriented north to south and east to west.

Within each vertical section, we identified the spherical location of peaks $(r, \theta, \varphi)$ with a returned backscatter power above $-50 \mathrm{~dB} V_{\text {RMS }}$. Doing so revealed a series of peaks traceable through increasing depth (Fig. 3). Although the radial distance of the peak to the antenna array $(r)$ and the angle from nadir $(\theta)$ can be accurately determined within each vertical section, the azimuth $(\varphi)$ is not yet constrained due to the pre-set orientation of the vertical sections ( $\varphi=0,90,180$, or $270^{\circ}$; Fig. 3). Therefore, using the traced peaks within each vertical section as a guide, we then located the identified peaks in 3-D through sequential horizontal sections, resolving the third spherical coordinate $\varphi$ (Fig. 3).

Range migration begins to have a significant effect when the number of linearly-spaced elements is at least $1+4 / B_{f}$, which is 7 for the parameters of the pRES system given $B_{f}=2 / 3$ (a fractional bandwidth of $200 / 300 \mathrm{MHz}$; Brennan and others, 2015). The configuration of the $8 \times 8$ planar MIMO antenna array (Fig. 2a) exceeds this limit very slightly, and therefore the effect of range migration is minimal and only marginally affects the outer limits of the scan angle range. Therefore for simplicity, we do not apply range migration correction. 
(a)
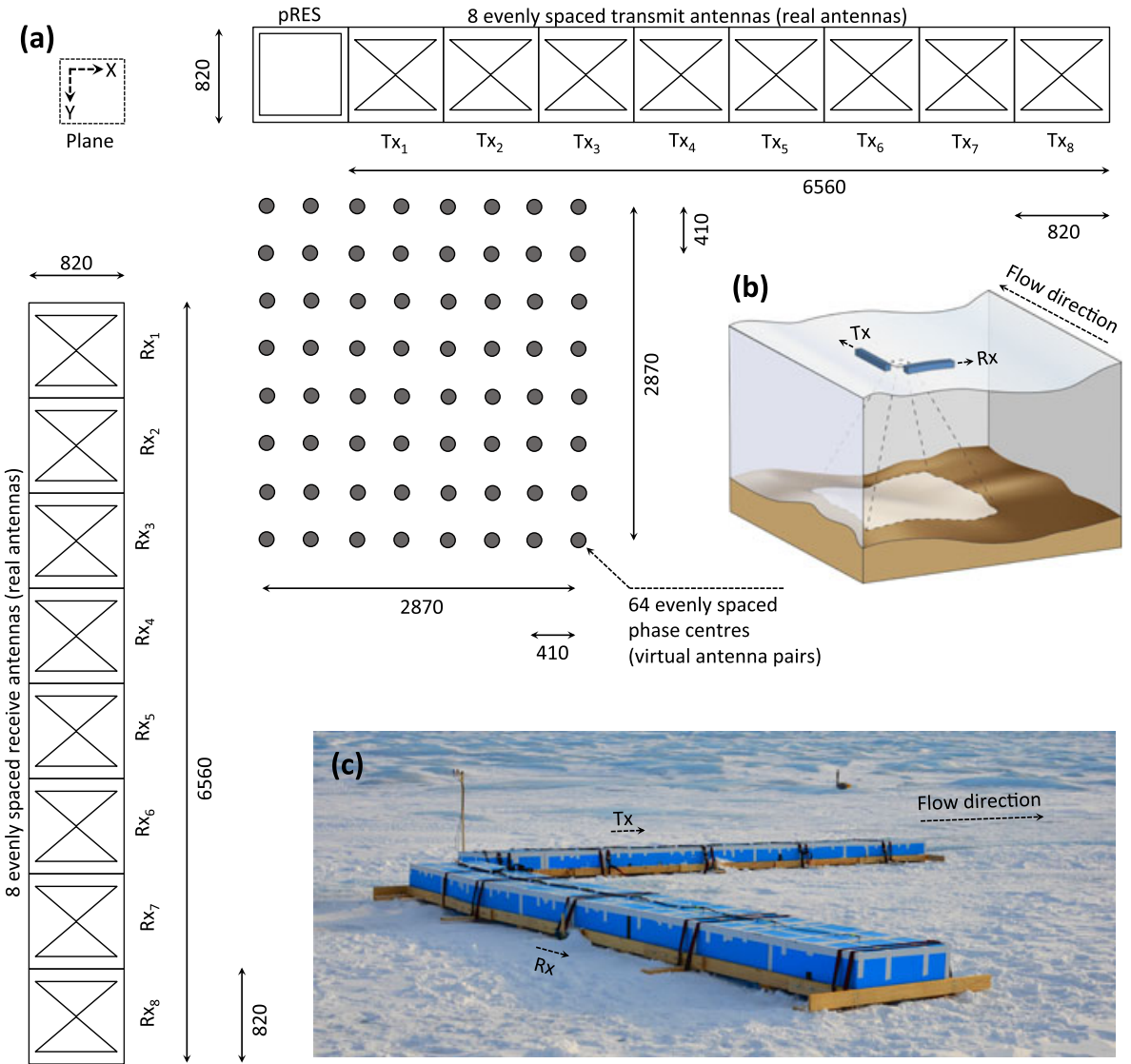

Fig. 2. (a) Schematic diagram (along the $X-Y$ plane, where the Z-axis points into the diagram) showing the field configuration of the planar MIMO antenna array, composed of 8 transmitting $(\mathrm{Tx})$ and 8 receiving (Rx) bowtie antennas oriented in two orthogonal linear arrays, producing 64 virtual antenna pairs. (b) Conceptual diagram showing the footprint of the deployed antenna array. (c) Photo of field setup of the MIMO antenna array at site $14 \mathrm{a}\left(70^{\circ} 31^{\prime} 02^{\prime \prime} \mathrm{N}, 49^{\circ} 55^{\prime} 50^{\prime \prime} \mathrm{W}\right.$ as of 7 May 2014; Fig. 1), with the principal direction of flow: oriented west-southwest $\left(262^{\circ}\right)$. All measurements shown are in $\mathrm{mm}$.

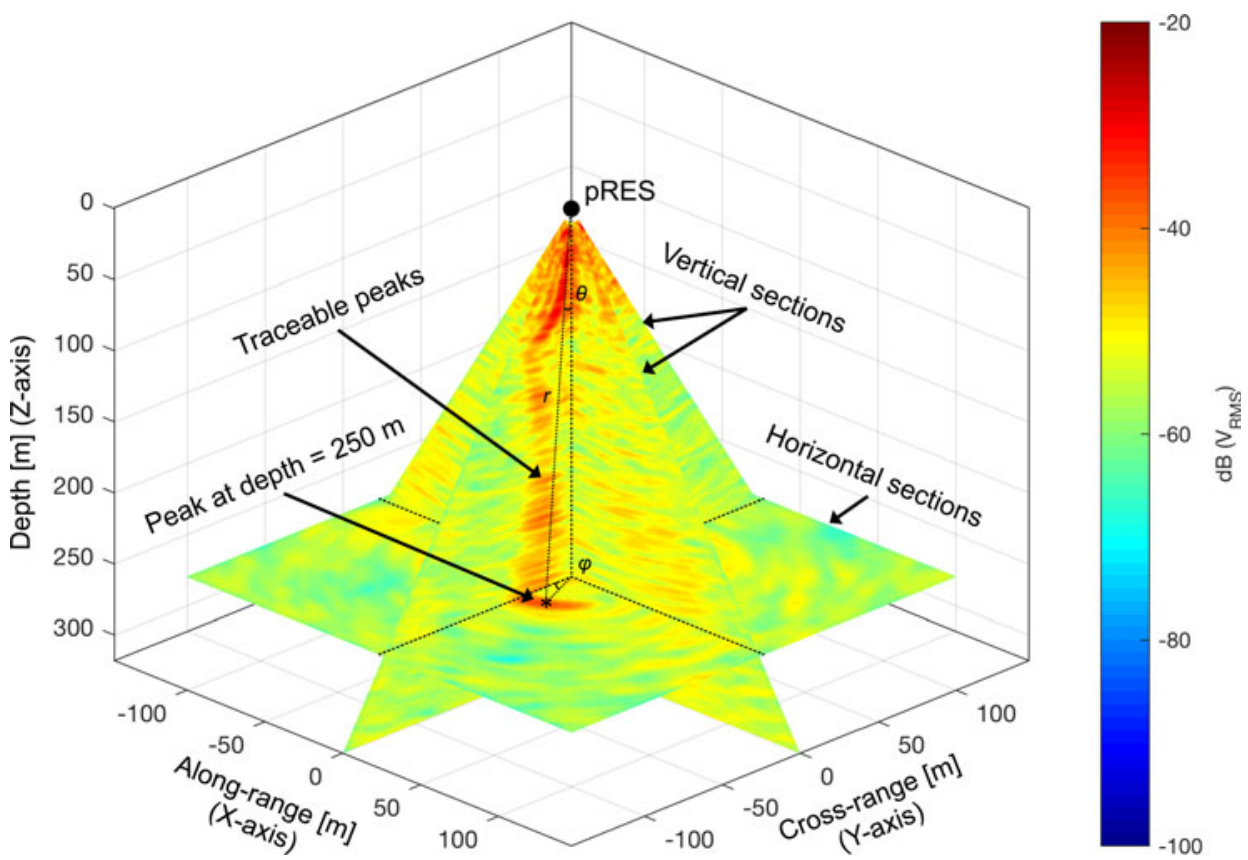

Fig. 3. Nomenclature of 2-D cross-sections. Within each vertical section, peaks in returned backscatter power are identified and can be traced with increasing depth. At specific depths, the location of these peaks was used to triangulate the peak within the corresponding horizontal section. 


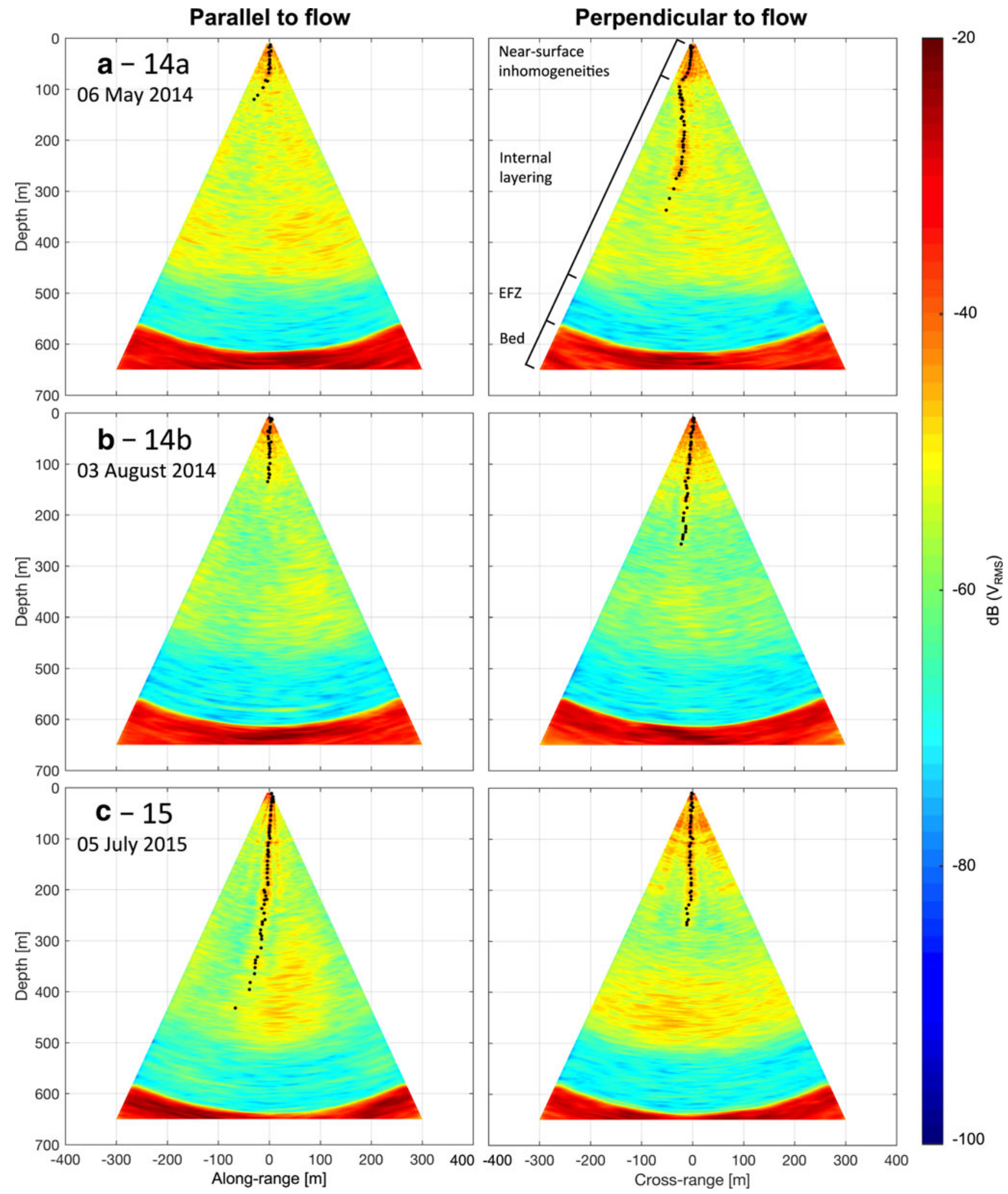

Fig. 4. 2-D vertical sections within $\mathrm{S} 30$ acquired along (left column) and across (right column) the ice flow direction $\left(262^{\circ}\right)$. Black dots show identified peaks in returned backscatter power $\left(>-50 \mathrm{~dB} \mathrm{~V}_{\mathrm{RMS}}\right)$ traceable through depth, and vertical bands indicating types of layering are shown in (a). Sections were acquired at (a) site 14a on 6 May 2014 (offset by $+12^{\circ}$; Table 1); (b) site 14b on 3 August 2014 ; and (c) site 15 on 5 July 2014. Fig. $1 \mathrm{~b}$ and Table 1 shows the location and orientation of each deployment within S30.

\section{IDENTIFICATION AND INTERPRETATION OF INTERNAL LAYERS}

\subsection{Vertical stratigraphy of the ice column}

All pRES vertical sections acquired on Store Glacier show similar internal stratigraphy through depth, with the sections divided into four distinct bands (Fig. 5). Through the majority of the vertical sections, a series of peaks, which we interpret to be dominant internal layers, can be traced from the ice surface (black dots, Fig. 5). The traced peaks all curve away from nadir with depth, and extend to considerable ( $300 \mathrm{~m})$ depths, particularly those aligned perpendicular 


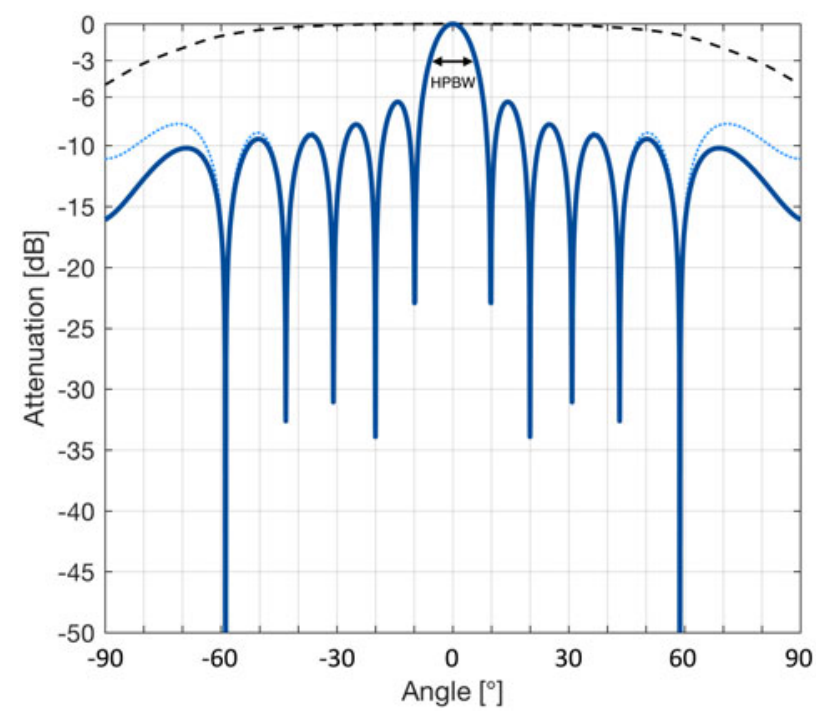

Fig. 5. Radiation patterns of the overall array ( $F$; solid blue), the element factor $\left(F_{\mathrm{e}}\right.$; dashed black) and the array factor $\left(F_{\mathrm{a}}\right.$; dotted blue) using the setup as described in Fig. 2a. The half-power beamwidth (HPBW) of both $F$ and $F_{\mathrm{a}}$, indicated by arrows, is $\pm 6^{\circ}$.

to flow (i.e. along the $Y-Z$ plane). Besides the identified peaks, there exists some clustering in reflections away from the traced peak trajectory, particularly between 300 and $500 \mathrm{~m}$ depth.

The upper $30-80 \mathrm{~m}$ of the vertical section is dominated by closely-spaced high $\left(-40-20 \mathrm{~dB} V_{\mathrm{RMS}}\right)$ signal strength reflections. We do not attribute the source of the observed near-surface clutter without further field investigations; however, these near-surface inhomogeneities could be due to any or a combination of (i) Fresnel diffraction within the near-field region (Yamaguchi and others, 1992); (ii) englacial heterogeneities (e.g. water-filled pockets, cracks, veins, conduits) within the upper glacier surface (Smith and Evans, 1972; Watts and England, 1976; Kanagaratnam and others, 2004); and (iii) presence of surface crevasses (Rignot and others, 2013; Colgan and others, 2016), of which the latter two are abundantly present at S30 (Hofstede and others, 2018).

Beyond depths of $500 \mathrm{~m}$, the returned signal strength drops markedly, indicating a $\sim 100 \mathrm{~m}$ thick transparent region of ice above the ice/bed interface. This region in our study is located close to an observed change in crystal fabric orientation transitioning to anisotropic Wisconsinaged ice detected from seismic experiments (Hofstede and others, 2018) and the onset of high deformation inferred from borehole-installed tilt sensors both conducted within S30 (Doyle and others, 2018). While the enhanced shearing observed at S30 may further deteriorate the presence of layers within this region, we are still able to detect some deep reflectors (e.g. at $580 \mathrm{~m}$ at site 14b), implying that the reduction in signal strength is caused by an attenuation in the power of the received signal. Further investigations are needed to provide definitive conclusions as to whether the lack of internal layers depth range represents these changes in ice properties.

The ice/bed interface, located between 600 and $640 \mathrm{~m}$ depth, is consistently identified in all sections as an abrupt increase in signal strength (+60 dB $\left.V_{\text {RMS }}\right)$. The signal strength is sustained beyond this range to at least $650 \mathrm{~m}$, which is the lower boundary applied to our images. For reasons discussed below, we discount the curved bed geometry seen in all sections as an artefact of processing, and instead focus on the traceable peaks and their representation as internal layers.

\subsection{Simulation of the vertical section}

Although at first glance the traced peaks identified in all vertical sections within S30 (Fig. 5) may visually resemble surface crevasses or large moulins (e.g. Arcone and Delaney, 2000), the minimum depths to which all the traced peaks at least propagate to $(>100 \mathrm{~m})$, are all of order of magnitude beyond field observations of crevasses and likely would not penetrate deeper than $\sim 30 \mathrm{~m}$ without the presence of meltwater due creep closure from the stress supplied by the surrounding ice (Colgan and others, 2016). Therefore, to determine the cause of these traced peaks, we conducted a series of simulations that reconstructs a synthetic 2-D glacier vertical section varying the parameters of the array factor of the antenna array deployed in the field (Fig. 4; see Appendix). The array factor $\left(F_{\mathrm{a}}\right)$ characterises how the power of a radar-transmitted signal is spatially distributed (i.e. the height and width of the main lobe and sidelobes, and the presence of grating lobes) across the swath of scanning angles $(\theta)$ and combined with the radiation pattern of a single virtual antenna pair (element factor; $F_{\mathrm{e}}$ ) produces the transmitted and received signal of the overall antenna array $(F)$ :

$$
F(\theta)=F_{\mathrm{e}}(\theta) F_{\mathrm{a}}(\theta)=F_{\mathrm{e}}(\theta) \sum_{k=1}^{K} \exp \left[-j(K-k) k_{0} \delta \sin (\theta)\right]
$$

for a linear system of $K$ virtual antenna pairs uniformly spaced $\delta \mathrm{m}$ apart (Huang and others, 2011), where $k_{0}=2 \pi / \lambda_{\mathrm{c}}$ is the free space wave number. The antenna array's performance can be optimised by manipulating Eqn (4)'s key parameters, namely (i) the element factor $\left(F_{\mathrm{e}}\right)$; (ii) the number of linear virtual antenna pairs $(K)$; and (iii) the separation between virtual antenna pairs $(\delta)$. Accordingly, the series of simulations (Fig. S1-3 in Supporting Information) varied these three parameters.

Specifically, the simulations track the transmission and reflection of a signal beam (Eqn 4) across a range of angles through depth, and reconstructs a vertical glacier alongflow section by vertically stacking the received signals through depth, as described in the Appendix. The signal beam was generated from an 8-antenna linear array using the array factor derived from the field configuration (Fig. 2a). The synthetic glacier vertical section (synthetic section) used as input to all simulations (Fig. 6a) included several artificial features typical of radargrams of ice sheets, notably four internal layers at various slope angles and a flat, subglacial layer with an undulating bed and a small topographic protuberance $20 \mathrm{~m}$ high, $50 \mathrm{~m}$ wide, with its apex located $100 \mathrm{~m}$ left of nadir (equivalent to $-9.46^{\circ}$; Appendix).

By assuming internal layers to be specular reflectors (Drews et al. 2009, Holschuh et al. 2014, Cavitte et al. 2016; Appendix), the transmitted signal is only reflected from the internal layer when the incident ray beam path is at or close to normal relative to the layer plane (Fig. 7). The incorporation of this assumption into the simulation importantly reconstructs the synthesised internal layers (Fig. 6a) into a peak of concentrated returned backscatter visually 

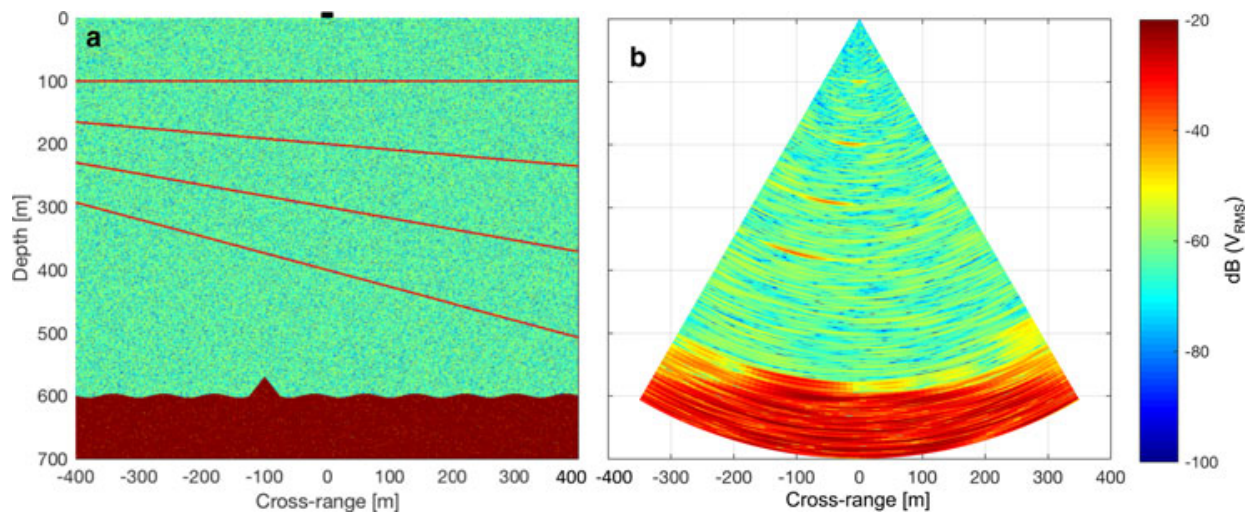

Fig. 6. (a) Synthetic glacier vertical section as input to model simulations. The location of the array is at $(0,0)$, indicated by a black square. (b) Corresponding reconstructed glacier vertical section parameterised using the setup as described in Fig. 2a.

similar to field-acquired sections at S30 (Fig. 5). Geometrically, the centre of the simulated peak, where returned backscatter power is highest, is normal to the slope of the synthesised internal layer, and the depth of the peak corresponds to the respective layer's mean depth (Fig. 6b). It then follows that the slope of the synthesised internal layers corresponds to the peak's angle from nadir (Fig. 7).

\subsection{Interpretation of internal layer slopes}

Based on the results from the simulations, we plot the peaks identified as internal layers in Fig. 5 in 3-D to better illustrate the dipping layer (Fig. 8). Most layers within all three-radargrams slope from South to North, and the azimuth and direction of these layers agree closely with the basal topography (Fig. 1). This agreement is predominantly the case in the cross-flow direction, where the bed elevation rises to the south (Fig. 1c), but also to a lesser extent along-flow where the glacier is flowing downhill (Fig. 1d). The magnitude of the slopes observed was small overall $\left(\sim 2^{\circ}-6^{\circ}\right)$ and generally constant in tilt through depth, with the exception of more

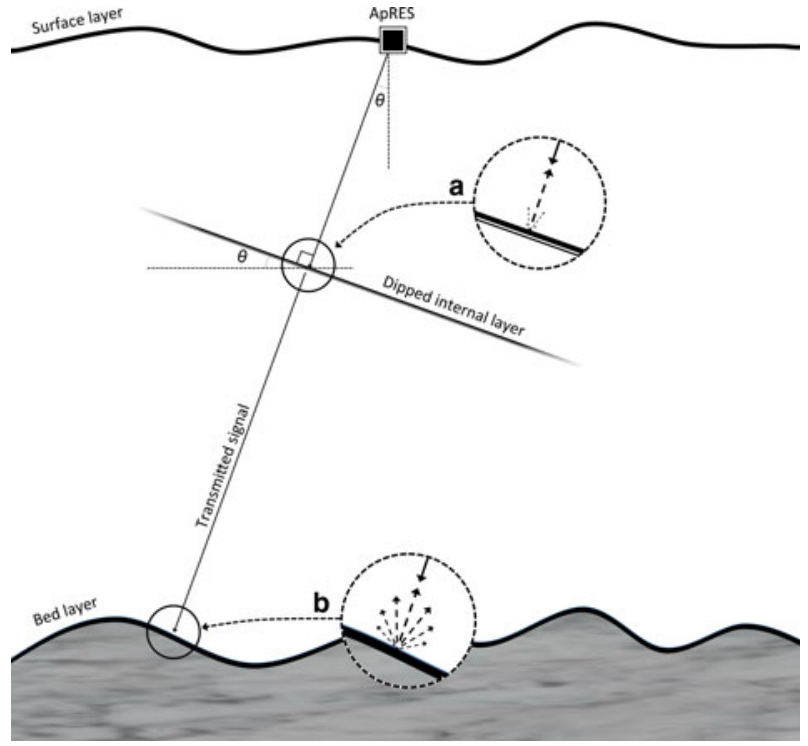

Fig. 7. Model for the scattering properties of (a) a dipped internal layer, which assumes a specular reflecting interface; and (b) a basal interface, which assumes a more diffuse interface. Further information is given in the Appendix. steeply-dipping layers at $\sim 100 \mathrm{~m}$ depth with slopes as high as $15^{\circ}$ beneath site 14a (Fig. 8). Although it is unlikely that moulins, water pockets, or other point scattering sources would have caused these dipping layers, as their scattering functions (spread in the 2-D image) will be wider than a specular layer, larger features such as cross-cutting crevasses or refrozen englacial water can potentially reflect anomalously high slopes if they are wide enough (a significant fraction of a Fresnel zone).

The stratigraphy of internal layers is considered representative of past and present variations in ice flow. Regions of stable and/or slow flow often develop reflector slopes that monotonically change with depth, while spatial variations in ice flow disrupt regular internal layering $(\mathrm{Ng}$ and Conway, 2004; Holschuh and others, 2017). These variations mostly result from changes to the local strain field as the ice transitions between slow and fast flow regimes; alternatively, the strain field can also be disrupted by changes to the roughness of the underlying subglacial topography (Hubbard and others, 2000; Siegert and others, 2003; Hindmarsh and others, 2006; Bingham and others, 2015). Indeed, prior seismic analysis of S30 conducted by Hofstede and others (2018) revealed variations in the internal layering and the nature of the ice/bed interface within the study area, including a steep symmetric syncline located $\sim 400 \mathrm{~m}$ north of array 14a (Fig. 1c) that matches the primary orientation of the identified sloping internal layers (Fig. 8). The syncline is thought to have formed in response to a combination of converging flow and basal melting. This observation, together with small-scale variations in subglacial properties, suggest that the presence of patches of different basal slipperiness is associated with variable amounts of water at the ice/bed interface. While quantitative analysis of internal layering typically requires numerical modelling of ice flow, given our knowledge of S30's subglacial environment, we believe that the spatial variability of observed englacial layer slopes through depth (Fig. 8) could be attributed to the patchy nature of the underlying bed that results in local stress variations dynamically deforming the overlying ice (Ryser and others, 2014). Such variations area is able to induce anomalously steep layer slopes in the middle of the ice column, allowing slopes to deviate from expected monotonic trends (Holschuh and others, 2017). Further analysis of the subglacial conditions at the local study site, together with additional imaging pRES deployments, are needed to conclusively explain the contrasts in slope gradients, especially within the upper $100 \mathrm{~m}$ between the three sites at S30. 

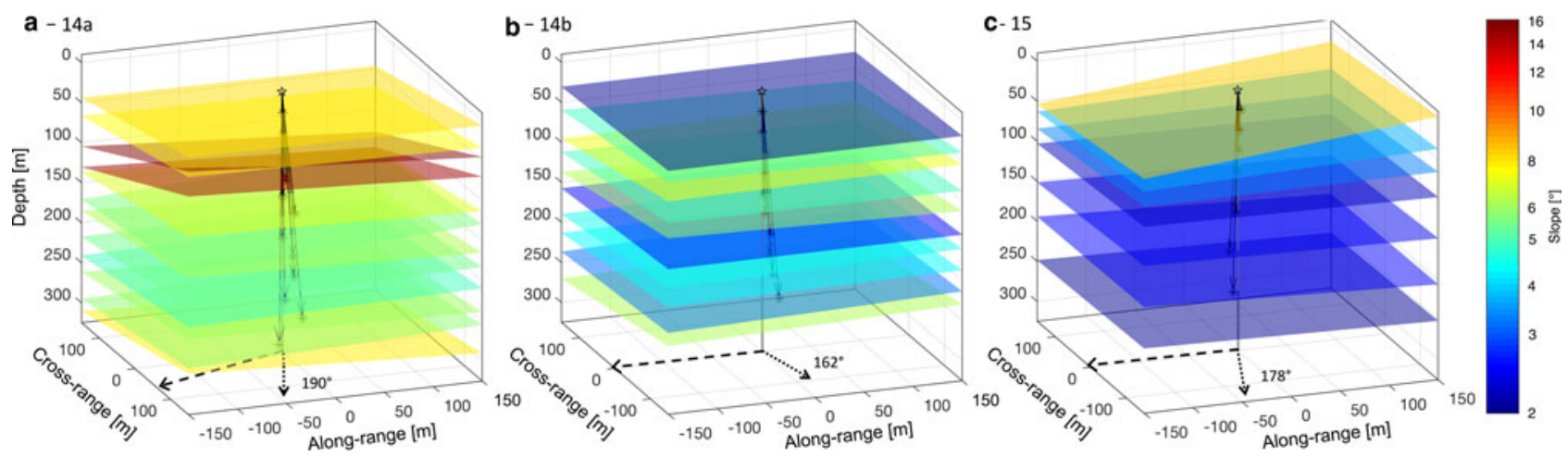

Fig. 8. 3-D planes representing the orientation and slope of identified internal layers $\left(>-50 \mathrm{~dB} \mathrm{~V}_{\mathrm{RMS}}\right.$ ) within S30 on Store Glacier. The internal layering profiles were derived from data acquired at sites (a) 14a on 6 May 2014; (b) 14b on 3 August 2014 ; and (c) 15 on 5 July 2015. The orientation of the three radar arrays is shown in Fig. 1b. The principal vector normal to the dipped layers (dotted arrow) are shown relative to true north $\left(0^{\circ}\right)$, and the principal direction of flow (dashed arrow) is oriented west of southwest $\left(262^{\circ}\right)$. The magnitude of the latter two vectors are on the $X-Y$ plane and not true to scale.

Studies of englacial layers, and their significance within the context of past and present ice flow dynamics, have so far only been based on 2-D profiling, with the third dimension, if present, projected through interpolation (e.g. Bingham and others, 2015; Winter and others, 2015). Such studies usually require ground- or air-based radar traverses that typically demand extensive logistical support. The advent of an instrument to measure the 3-D variability of internal layers with depth represents an additional method to investigate the ice flow structure over a large spatial area. In particular, the use of multiple imaging pRES arrays may complement traditional surveys in identifying potential ice-coring and/or subglacial access hot-water drilling sites, both of which require prior knowledge of the internal layer geometry to understand the local ice flow regime.

Past studies using pRES have tracked the vertical movement of internal layers through time, and have used this information to extract basal melt rates beneath Antarctic ice shelves (Corr and others, 2002; Jenkins and others, 2006; Dutrieux and others, 2014; Nicholls and others, 2015; Marsh and others, 2016). As the instrument detects internal layers only when the antenna beam is near perpendicular relative to the layer plane (Fig. 7a), tracking the englacial vertical velocity of dipped layers through time in a single depth dimension, similar to previous studies using a quasi-monostatic configuration (e.g. Kingslake and others, 2014, 2016), may produce erroneous vertical strain values. Specifically, if the ice column contains steep or highly variable layering, the measured vertical strain may be inflated due to the pRES partially capturing the horizontal movement of internal layers in addition to their vertical advection. Application of the pRES in MIMO configuration therefore enables the correction of off-nadir effects in the apparent vertical strain signal through its ability to partition the horizontal and vertical components of internal layer advection through time.

\section{RESOLVING THE BASAL LAYER}

So far, we have considered only the ability of pRES to investigate the geometry of internal layers without discussion of the curved bed layer observed in the field-acquired vertical sections (Fig. 5). To determine the cause of this artefact, we return to the output image of the simulation (Fig. 6b), which visually reproduced the same characteristic curve despite using an overall flat bed as input (Fig. 6a). At a smaller scale, the simulation was also unable to recreate the sinusoidal rough bed: the subglacial topographic protuberance in the synthetic profile was reconstructed as a shallow $(\sim 20 \mathrm{~m})$, but broad $(\sim 150 \mathrm{~m})$ protuberance superimposed above the curved bed roughly at the correct location $\left(-9.46^{\circ}\right.$ from nadir), and repeated across the curved bed (Fig. 6b). Considering the array's radiation pattern (Fig. 4, Eqn 4), the ability of the antenna array to resolve spatial wavelengths at the ice/bed interface is directly related to the angular acuity produced by the overall array. The high sidelobe power of the overall field-based array radiation pattern, spaced at $12.5^{\circ}$ angular intervals, is primarily responsible for the horizontal repetition of the protuberance, while its half-power beamwidth (HPBW) at $\pm 6^{\circ}$ is too wide to significantly resolve the $\sim 80 \mathrm{~m}\left(4^{\circ}\right)$ spatial wavelength undulations at the bed. Because the single protuberance at the bed is not a repeating signal, it has a range of spatial wavelengths, of which only the longer of these wavelengths is resolved by the array signal. In other words, the HPBW of the overall array factor determines the angular resolution of the output image, while its gain amplifies features within the ice column over unwanted clutter.

Given the importance of the array's radiation pattern on imaging the ice column and the basal topography, we modified the simulation's array factor to best reconstruct the input basal conditions by increasing the virtual antenna separation $(\delta)$ from 0.74 to $1 \times \lambda_{\mathrm{c}}$ and increasing the number of virtual antenna pairs (K) to 32 elements (Fig. 9). As the directivity of the beam increases with both $\delta$ (Fig. S2) and $K$ (Fig. S3), the reconstructed section was able to resolve the undulations in basal topography with a significantly higher angular resolution, and better characterise the size and shape of the subglacial protuberance.

\section{SUGGESTIONS FOR FUTURE DEPLOYMENTS}

As with all antenna systems, there exists a tradeoff between gain and beamwidth (Visser, 2005); however, correct modifications to the element separation distance $(\delta)$ and the number of linear elements $(K)$ will likely improve the imaging quality of both internal layer slopes and the basal topography in future deployments. From our study, we found that $\delta$ is itself secondary compared with $K$. Given the 


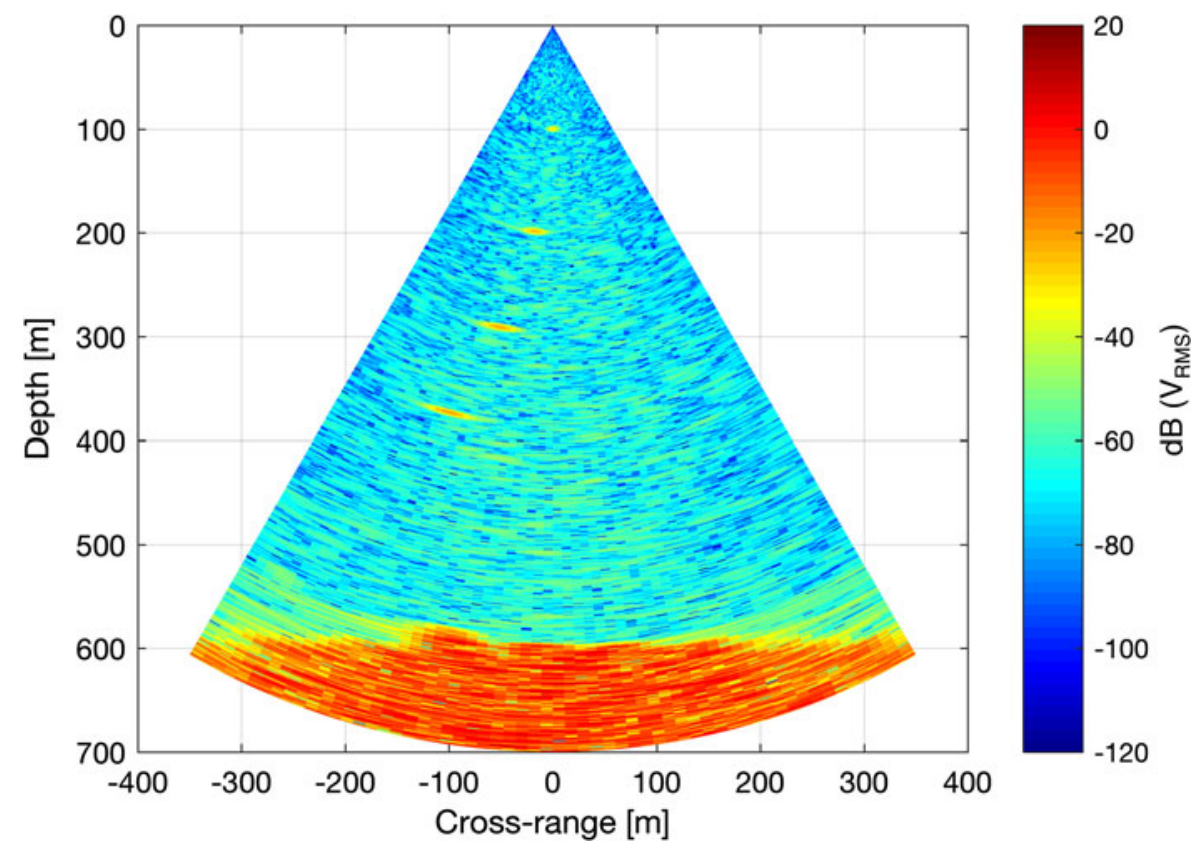

Fig. 9. Reconstructed glacier vertical profile, using a linear 32-element broadside array setup with the separation of virtual antenna pairs set at $\delta=1 \times \lambda_{\mathrm{c}}$, and a theoretical directive beam $\left(\mathrm{HPBW}= \pm 30^{\circ}\right)$.

angular swath used in the simulations within this study $\left( \pm 30^{\circ}\right)$, we suggest $\delta$ to be roughly equivalent to the central wavelength of the transmitted signal. Doing so will increase the likelihood of constraining internal layer slopes and resolving irregularities in the basal topography. Having the elements too widely spaced risks aliasing the signal returns via the presence of grating lobes (Fig. S2d), while too narrow an element separation reduces the directivity and gain of the signal. (Fig. S2a). Similarly, a higher $K$ value increases the angular acuity and therefore the resulting image's angular resolution (Fig. S3), effectively resolving smaller wavelengths manifested within the bed.

In our simulations (see Appendix), we simplify the scenario by using a linear array with a corresponding bed varying in one direction to reproduce the along-flow section of the ice. As a planar array, similar to our field configuration (Fig. 2a), is simply a series of stacked linear arrays, the number of virtual antenna pairs will either need to be multiplied or the array be towed to create a planar synthetic aperture (e.g. Walford and Kennett, 1989; Paden and others, 2010) in order to image the bed in two directions to accurately resolve a 3-D representation of the bed roughness. The current version of the pRES unit, which has the capability of switching between up to eight Tx and eight Rx antenna pairs, limits the maximum number of pairs to 64 elements in a planar arrangement, or 32 pairs in a linear arrangement. Therefore, given the current instrument capabilities, there exists a tradeoff between 3-D imaging of internal layer slopes and resolving the basal topography in 2-D. Characterising internal layers in 3-D with a planar setup (e.g. $8 \times 8$ virtual antenna pairs) can be traded for a maximum-element linear array $(32 \times 1$ virtual antenna pairs) witha higher 2-D resolution to better resolve the bed.

As instrument costs often play a significant factor in the choice of materials used, the ideal antenna would have to be low cost, easily constructed, transportable and robust to withstand the harsh conditions of the polar regions.
Additional simulations varying the element factor (Fig. S1) show that the choice of antenna merely limits the width of the usable swath, which is approximately equivalent to its HPBW and exerts no influence over the array factor Eqn (4). The current size of the physical bowtie antennas used in this study $(820 \mathrm{~mm} \times 820 \mathrm{~mm}$; Fig. 2a), in addition to their simplicity and low associated costs, have a HPBW of $\pm 80^{\circ}$ and were optimised to operate at the air/ice interface. If the antenna size was reduced, a higher frequency would be required to maintain the current antenna properties, which ultimately reduces the range of the system from the internal losses from englacial signal scattering.

\section{SUMMARY AND CONCLUSIONS}

By tracking the relative range change of internal and basal reflectors, studies involving pRES have demonstrated its potential for measuring vertical strain within ice sheets (Kingslake and others, 2014, 2016) and basal melt rates beneath ice shelves (Corr and others, 2002; Jenkins and others, 2006; Dutrieux and others, 2014; Nicholls and others, 2015; Marsh and others, 2016). Here, we describe the use of the instrument with a 16-antenna MIMO array to image internal layers in a fast-flowing outlet glacier that drains a $35000 \mathrm{~km}^{2}$ catchment on the Greenland ice sheet. The capability of the instrument to measure and partition the movement and slope of internal layers in three dimensions sheds new light on the vertical stratigraphy in a region of complex ice flow, with the potential to greatly improve estimates of vertical velocities and strain rates within such regions. We use a forward model to optimise and improve the angular resolution of the bed echo layer, demonstrating the importance of the array factor to reflect on the specific purposes of the deployment. In addition to its lower power consumption and lightweight, pRES offers novel possibilities when applied in a MIMO configuration. 


\section{SUPPLEMENTARY MATERIAL}

The supplementary material for this article can be found at https://doi.org/10.1017/jog.2018.54.

\section{ACKNOWLEDGMENTS}

This research was funded by the UK Natural Environmental Research Council grants NE/K005871/1 (to PC) and NE/ $\mathrm{K} 006126$ (to $\mathrm{BH}$ and $\mathrm{AH}$ ), a NASA Cryospheric Science grant NNX16AJ95G (to DMS) and grants from the University of Cambridge Fieldwork Fund and Chung Wei Yi Co. Ltd. (to TJY). We thank Marion Bougamont and Joe Todd for assistance in choosing the field site and ancillary data generated by numerical models; Leo Nathan and Coen Hofstede for assistance in the field; the crew of SV Gambo for logistical support; and Ann Andreasen and the Uummannaq Polar Institute who generously helped and provided local support. PC was the lead PI of the project. Authors are listed according to contribution. The codes for processing the field-collected datasets and the simulation, along with an example dataset, will be submitted to the Remote Sensing Code Library (RSCL; http://rscl-grss.org/ about.php) shortly after this manuscript is published. Until that time, the codes and datasets are available by request from the corresponding author.

\section{REFERENCES}

Arcone SA and Delaney AJ (2000) GPR images of hidden crevasses in Antarctica. Eighth Int. Conf. Ground Penetrating Radar, 4084, 760-765 (doi: 10.1117/12.383512)

Bamber JL and 10 others (2013) A new bed elevation dataset for Greenland. Cryosphere, 7, 499-510 (doi: 10.5194/tc-7-4992013)

Bingham RG and 9 others (2015) Ice-flow structure and ice dynamic changes in the Weddell Sea sector of West Antarctica from radarimaged internal layering. J. Geophys. Res. Earth Surf., 120(4), 656-670 (doi: 10.1002/2014JF003291)

Box JE and Decker DT (2011) Greenland marine-terminating glacier area changes: 2000-2010. Ann. Glaciol., 52(59), 91-98 (doi: 10.3189/172756411799096312)

Brennan PV, Lok LB, Nicholls KW and Corr HFJ (2014) Phase-sensitive FMCW radar system for high-precision Antarctic ice shelf profile monitoring. IET Radar, Sonar and Navigation, 8(7), 776786 (doi: 10.1049/iet-rsn.2013.0053)

Brennan PV, Rahman S and Lok LB 2015) Range migration compensation in static digital-beamforming-on-receive radar. IET Radar, Sonar Navigation, 9(9), 1323-1329 (doi: 10.1049/ietrsn.2014.0355)

Cavitte MGP and 7 others (2016) Deep radiostratigraphy of the East Antarctic plateau: connecting the Dome $\mathrm{C}$ and Vostok ice core sites. J. Glaciol., 62(232), 323-334 (doi: 10.1017/jog.2016.11)

Christianson K and 6 others (2016) Basal conditions at the grounding zone of Whillans Ice Stream, West Antarctica, from ice-penetrating radar. J. Geophys. Res. Earth Surf., 121(11), 1954-1983 (doi: 10.1002/2015JF003806)

Colgan WT and 6 others (2016) Glacier crevasses: observations, models, and mass balance implications. Rev. Geophys., 54, 119-161 (doi: 10.1002/2015RG000504)

Corr HFJ, Jenkins A, Nicholls KW and Doake CSM (2002) Precise measurement of changes in ice-shelf thickness by phase-sensitive radar to determine basal melt rates. Geophys. Res. Lett., 29(8), 14 (doi: 10.1029/2001GL014618)

Dahl-Jensen D and 9 others (1997) A search in North Greenland for a new ice-core drill site. J. Glaciol., 43(144), 300-306 (doi: 10.3189/S0022143000003245)
Dahl-Jensen D, Gundestrup N, Gogineni P and Miller H (2003) Basal melt at North GRIP modeled from borehole, ice-core and radio-echo sounder observations. Ann. Glaciol., 37(1), 207212 (doi: 10.3189/172756403781815492)

Doyle SH and 7 others (2018) Physical conditions of fast glacier flow: 1. measurements from boreholes drilled to the bed of Store Glacier, West Greenland. J. Geophys. Res. Earth Surf., 123(2), 324-348 (doi: 10.1002/2017JF004529)

Drewry DJ and Meldrum DT (1978) Antarctic airborne radio echo sounding, 1977-78. Polar Record, 19(120), 267 (doi: 10.1017/ S0032247400018271)

Drews $\mathrm{R}$ and 7 others (2009) Layer disturbances and the radio-echo free zone in ice sheets. Cryosphere, 3, 195-203

Dutrieux P and 6 others (2014) Basal terraces on melting ice shelves. Geophys. Res. Lett., 41(15), 5506-5513 (doi: 10.1002/ 2014GL060618)

Evans S and Smith BME (1969) A radio echo equipment for depth sounding in polar ice sheets. J. Phys. E: Sci. Instrum., 2(2), 131-136 (doi: 10.1088/0022-3735/2/2/302)

Harrison $\mathrm{CH}, 1973$ ) Radio echo sounding of horizontal layers in ice. J. Glaciol., 12(66), 383-397

Hindmarsh RCA, Leysinger Vieli GJMC, Raymond MJ and Gudmundsson GH (2006) Draping or overriding: the effect of horizontal stress gradients on internal layer architecture in ice sheets. J. Geophys. Res. Earth Surf., 111(2), F02018 (doi: 10.1029/2005JF000309)

Hofstede C and 7 others (2018) Physical conditions of fast glacier flow: 2. variable extent of anisotropic ice and soft basal sediment from seismic reflection data acquired on Store Glacier, West Greenland. J. Geophys. Res. Earth Surf., 123(2), 349-362 (doi: 10.1002/2017JF004297)

Holschuh N, Christianson K and Anandakrishnan S (2014) Power loss in dipping internal reflectors, imaged using ice-penetrating radar. Ann. Glaciol., 55(67), 49-56 (doi: 10.3189/ 2014AoG67A005)

Holschuh N, Parizek BR, Alley RB, Anandakrishnan S (2017) Decoding ice sheet behavior using englacial layer slopes. Geophys. Res. Lett., 44(11), 1-20 (doi: 10.1002/2017GL073417)

Howat IM, Box JE, Ahn Y, Herrington A, McFadden EM (2010) Seasonal variability in the dynamics of marine-terminating outlet glaciers in Greenland. J. Glaciol., 56(198), 601-613 (doi: 10.3189/002214310793146232)

Howat IM, Negrete A and Smith BE (2014) The Greenland Ice Mapping Project (GIMP) land classification and surface elevation data sets. Cryosphere, 8(4), 1509-1518 (doi: 10.5194/tc-8-15092014)

Huang Y and 5 others (2011) FMCW based MIMO imaging radar for maritime navigation. Prog. Electromagn. Res., 115, 327-342

Hubbard BP, Siegert MJ and McCarroll D (2000) Spectral roughness of glaciated bedrock geomorphic surfaces: implications for glacier sliding. J. Geophys. Res., 105(B9), 21295 (doi: 10.1029/ 2000JB900162)

Jenkins A, Corr HFJ, Nicholls KW, Stewart CL and Doake CSM (2006) Interactions between ice and ocean observed with phase-sensitive radar near an Antarctic ice-shelf grounding line. J. Glaciol., 52(178), 325-346 (doi: 10.3189/17275650678 1828502)

Jezek K and 6 others (2011) Radar images of the bed of the Greenland Ice Sheet. Geophys. Res. Lett., 38(1), 1-5 (doi: 10.1029/2010GL045519)

Kanagaratnam P, Gogineni SP, Ramasami V and Braaten D (2004) A wideband radar for high-resolution mapping of near-surface internal layers in glacial ice. IEEE Trans. Geosci. Remote Sens., 42(3), 483-490 (doi: 10.1109/TGRS.2004.823451)

Keisling BA and 8 others (2014) Basal conditions and ice dynamics inferred from radar-derived internal stratigraphy of the northeast Greenland Ice Stream. Ann. Glaciol., 55(67), 127-137 (doi: 10.3189/2014AoG67A090)

Kennett MI 1989) A possible radio-echo method of locating englacial and subglacial waterways. Ann. Glaciol., 13, 135-139 
King EC, Hindmarsh RCA and Stokes CR (2009) Formation of megascale glacial lineations observed beneath a West Antarctic Ice Stream. Nat. Geosci., 2, 585-588 (doi: 10.1038/NGEO581)

Kingslake J and 9 others (2014) Full-depth englacial vertical ice sheet velocities measured using phase-sensitive radar. J. Geophys. Res. Earth Surf., 119(12), 2604-2618 (doi: 10.1002/2014JF003275)

Kingslake J, Martín C, Arthern RJ, Corr HFJ and King EC (2016) Iceflow reorganization in West Antarctica $2.5 \mathrm{kyr}$ ago dated using radar-derived englacial flow velocities. Geophys. Res. Lett., 43 (17), 9103-9112 (doi: 10.1002/2016GL070278)

Li J, Stoica P and Zheng X (2008) Signal synthesis and receiver design for mimo radar imaging. IEEE Trans. Signal. Process., 56 (8), 3959-3968 (doi: 10.1109/TSP.2008.923197)

Lok LB, Brennan PV, Ash M and Nicholls KW (2015) Autonomous phase-sensitive radio echo sounder for monitoring and imaging Antarctic ice shelves. 8th International Workshop on Advanced Ground Penetrating Radar, IWAGPR 2015, 1-4 (doi: 10.1109/ IWAGPR.2015.7292636)

Lythe M, Vaughan DG and the BEDMAP Consortium (2001) BEDMAP: a new ice thickness and subglacial topographic model of Antarctica. J. Geophys. Res., 106(B6), 11335-11351 (doi: 10.1029/2000JB900449)

MacGregor JA and 9 others (2015) Radiostratigraphy and age structure of the Greenland Ice Sheet. J. Geophys. Res. Earth Surf., 120, 212-241 (doi: 10.1002/2014JF003215)

Marsh OJ, Fricker HA, Siegfried MR, Christianson K (2016) High basal melt rates initiate a channel at the grounding line of Ross Ice Shelf, Antarctica. Geophys. Res. Lett., 43(1), 250-255 (doi: 10.1002/2015GL066612)

Morlighem M and 6 others (2016) Modeling of Store Gletscher's calving dynamics, West Greenland, in response to ocean thermal forcing. Geophys. Res. Lett., 43(6), 2659-2666 (doi: 10.1002/2016GL067695)

Morlighem M and 31 others (2017) Bedmachine v3: Complete bed topography and ocean bathymetry mapping of Greenland from multibeam echo sounding combined with mass conservation. Geophys. Res. Lett., 44(21), 11051-11061 (doi: 10.1002/2017GL074954)

$\mathrm{Ng} F$ and Conway HB (2004) Fast-flow signature in the stagnated Kamb Ice Stream, West Antarctica. Geology, 321(4), 481-484 (doi: 10.1130/G20317.1)

Nicholls KW and 5 others (2015) A ground-based radar for measuring vertical strain rates and time-varying basal melt rates in ice sheets and shelves. J. Glaciol., 61(230), 1079-1087 (doi: 10.3189/2015JoG15J073)

Paden JD, Akins T, Dunson D, Allen C and Gogineni PS (2010) Icesheet bed 3-D tomography. J. Glaciol., 56(195), 3-11 (doi: 10.3189/002214310791190811)

Plewes LA and Hubbard B (2001) A review of the use of radio-echo sounding in glaciology. Prog. Phys. Geogr., 25(2), 203-236 (doi: 10.1177/030913330102500203)

Rignot E and Mouginot J (2012) Ice flow in Greenland for the international polar year 2008-2009. Geophys. Res. Lett., 39(11), 1-7 (doi: 10.1029/2012GL051634)

Rignot E, Mouginot J, Larsen CF, Gim Y and Kirchner D (2013) Lowfrequency radar sounding of temperate ice masses in Southern Alaska. Geophys. Res. Lett., 40(20), 5399-5405 (doi: 10.1002/ 2013GL057452

Robin GdQ, Drewry DJ and Meldrum DT (1977) International studies of ice sheet and bedrock. Philos. Trans. R. Soc. Lond. B, Biol. Sci., 279, 185-196 (doi: 10.1098/rstb.2009.0030)

Ryser C and 7 others (2014) Caterpillar-like ice motion in the ablation zone of the Greenland Ice Sheet. J. Geophys. Res. Earth Surf., 119, 2258-2271 (doi: 10.1002/2013JF003067)

Schroeder DM, Blankenship DD, Raney RK and Grima C (2015) Estimating subglacial water geometry using radar bed echo specularity: application to Thwaites Glacier, West Antarctica. IEEE Geosci. Remote Sens. Lett., 12(3), 443-447 (doi: 10.1109/ LGRS.2014.2337878)

Siegert MJ, Payne AJ and Joughin I (2003) Spatial stability of Ice Stream D and its tributaries, West Antarctica, revealed by radio-echo sounding and interferometry. Ann. Glaciol., 37(1), 377-382 (doi: 10.3189/172756403781816022)

Sime LC, Karlsson NB, Paden JD and Prasad Gogineni S (2014) Isochronous information in a Greenland ice sheet radio echo sounding data set. Geophys. Res. Lett., 41(5), 1593-1599 (doi: 10.1002/2013GL057928)

Smith BME and Evans S (1972) Radio echo sounding: absorption and scattering by water inclusion and ice lenses. J. Glaciol., 11(61), 133-146

Todd JA and Christoffersen P (2014) Are seasonal calving dynamics forced by buttressing from ice mélange or undercutting by melting? Outcomes from full-Stokes simulations of Store Glacier, West Greenland. Cryosphere, 8, 2353-2365 (doi: 10.5194/tc-82353-2014)

Visser HJ (2005) Array and Phased Array Basics. Chichester, United Kingdom: Wiley-Blackwell, 1 st ed.

Walford MER and Harper MFL (1981) The detailed study of glacier beds using radio-echo techniques. Geophys. J. R. Astron. Soc., 67, 487-514 (doi: 10.5100/jje.9.113)

Walford MER and Kennett MI (1989) A synthetic-aperture radio-echo experiment at Storglaciären, Sweden. J. Glaciol., 35(119), 43-47

Watts RD and England AW (1976) Radio-echo sounding of temperate glaciers: ice properties and sounder design criteria. J. Glaciol., 17(75), 39-48

Weidick A (1995) Satellite image atlas of glaciers of the World Greenland. Technical report, U.S. Geological Survey

Winter K and 6 others (2015) Airborne radar evidence for tributary flow switching in Institute Ice Stream, West Antarctica: Implications for ice sheet configuration and dynamics. J. Geophys. Res. Earth Surf., 120(9), 1611-1625 (doi: 10.1002/2014JF003432)

Wu X and 5 others (2011) Ice sheet bed mapping with airborne SAR tomography. IEEE Trans. Geosci. Remote Sens., 49(10), 37913802 (doi: 10.1109/TGRS.2011.2132802)

Yamaguchi Y, Mitsumoto M, Kawakami A, Sengoku M and Abe T (1992) Detection of objects by synthetic aperture FM-CW radar. Electron. Commun. Jpn., Part 1, 75(3), 85-94

Young DA, Schroeder DM, Blankenship DD, Kempf SD and Quartini E (2016) The distribution of basal water between Antarctic subglacial lakes from radar sounding. Philos. Trans. R. Soc. A, Math. Phys. Eng. Sci., 374(2059), 20140297 (doi: 10.1098/rsta.2014.0297)

\section{APPENDIX: EXTENDED METHODS}

\section{Synthesised vertical ice section}

The model input for our simulation is a synthetic vertical ice section representing an along-flow section of an ice sheet of $800 \mathrm{~m} \times 700 \mathrm{~m}$. Within the vertical section, we introduced several artificial features: (i) four internal layers situated at $100,200,300$ and $400 \mathrm{~m}$ depth along the cross-range centre $(x=y=0 \mathrm{~m})$ with slopes of $0^{\circ}, 5^{\circ}, 10^{\circ}$ and $15^{\circ}$, respectively, with a uniform reflectivity of $-30 \mathrm{~dB} V_{\mathrm{RMS}}$ at nadir; (ii) a sinusoidal bed situated at a mean depth of 600 $\mathrm{m}$, with $\pi$ amplitude and spanning 10 wavelengths across the domain, with a uniform reflectivity of $-20 \mathrm{~dB} V_{\mathrm{RMS}}$ at nadir; (iii) A small subglacial topographic feature of $20 \mathrm{~m}$ in height and $50 \mathrm{~m}$ in width located $100 \mathrm{~m}$ off-nadir (equivalent to $9.46^{\circ}$ ); and (iv) presence of a thick layer of subglacial material situated immediately below the bed layer to the bottom of the section, with an isotropic reflectivity of -30 $\mathrm{dB} V_{\mathrm{RMS}}$ below the bed layer.

We assume the ice within this section to be homogeneous in composition, resulting in the dielectric properties of ice to be constant through depth and space. Though this is rarely the case, especially in areas of accumulation and/or fast flow, there exists only several profiles of ice composition 
from ice core records (e.g. Dahl-Jensen and others, 2003) and this assumption is often necessary, especially when the purpose of the experiment is exploratory, as in this simulation. Therefore, in addition to simplicity, we do not incorporate these additional scenarios into our simulations.

\section{Backscattering coefficient}

In order to make effective decisions regarding radar design, we need an expectation of the target's scattering characteristics. Although radar signal propagation through ice incurs increasing attenuation through depth as a result of radiation scattering and absorption (e.g. Plewes and Hubbard, 2001), this simulation assumes no power loss unless the signal interacts with designated layers within the vertical section for simplicity. Here, we characterise the backscattering coefficient $\sigma^{0}$ using a Gaussian distribution with respect to the angle of incidence $\alpha$, with an incoming beam angle normal to the layer reflecting all power back to the source, and a beam angle perpendicular to the layer reflecting no power back to the source:

$$
\sigma^{0}=\beta^{0} \gamma f(\alpha)
$$

where $\beta^{0}$ is the radar brightness of the layer, $f(\alpha)$ the distribution as a function of the angle of incidence $\alpha$, and $\gamma$ an adjustment factor dictating the spread (variance) of the distribution.

While internal layers are known to be specular reflectors (Drews and others, 2009; Holschuh and others, 2014; Cavitte and others, 2016, Fig. 7a), the ice/bed interface is in most places a diffuse reflector (Drews and others, 2009, Fig. 7b) and is often highly variable in specularity (Schroeder and others, 2015; Young and others, 2016).
Therefore, for the simulations within this paper, the value of $\gamma$ was set at 1 with respect to receiving the bed echo in the absence of definitive knowledge of the bed, while $\gamma$ was reduced to 0.025 for internal layers due to their high specularity (Drews and others, 2009; Holschuh and others, 2014; Cavitte and others, 2016).

\section{Antenna beam generation and synthesis}

For the purposes of the simulation, the antenna array was treated as a point located at the centre of the domain resting on the ice surface $(0,0)$ from where the beams are transmitted and received. A virtual beam is emitted from the array point into the ice vertical section as a function of the scanning angle, producing an array factor $F_{\mathrm{a}}$ with a field of vision constrained by the antenna's radiation pattern (Eqn 4). The beam then travels through the section at the designated steering angle, of which at each depth step, a proportion of the total energy is reflected back and received by the array through backscatter as a function of the two-way distance from the array.

The received power $\left(P_{r}\right)$ for each pixel at a specific distance $(d)$ and angle $(\theta)$ from the array is then a combination of the transmitted and received signals ( $F^{2}$ due to reciprocity) and the resulting backscattering coefficient $\left(\sigma^{0}\right)$ :

$$
P_{r}(\theta, d)=F(\theta, d)^{2} \sigma^{0}(\theta, d)
$$

Pixels were then synthesised through distance and angle to reproduce the input ice profile. 